\title{
Evaluating Rule Breaking Behavior in a Nigerian Protected Forest Reserve Area
}

\section{${ }^{* 1}$ AKINSOROTAN, OA; ${ }^{2}$ OGUNTUASE, BG; ${ }^{2}$ OLANIYI, OE; ${ }^{3}$ NNAMUKA, SS}

\author{
*1Department of Fisheries and Wildlife, College of Agriculture, Osun State University, Nigeria \\ *Corresponding Author Email: oluseun.akinsorotan@uniosun.edu.ng, Tel: +2348034931119 \\ ${ }^{2}$ Department of Ecotourism and Wildlife Management, Federal University of Technology, Akure, Nigeria. Email: \\ bukolaoguntuase@gmail.com;oeolaniyi@futa.edu.ng \\ ${ }^{3}$ Department of Ecotourism and Wildlife Management, University of Ibadan, Ibadan, Nigeria \\ Email: kristzjek@gmail.com
}

\begin{abstract}
This paper investigated the rule breaking conduct in a Nigerian protected forest reserve area in order to exploit natural resources using Randomized Response Technique (RRT) for data collection. Evident from this study show a higher proportion of the residents surrounding Oba Hills Forest Reserve, Nigeria illegally poach, encroach to farm, extract timber, gather firewood and graze their domestic animals in the conservation area. With the high level of noncompliance to the conservation rules in this study, there is a need for the government and conservation managers to identify and harness social norms that encourage compliance, as well as increasing probabilities of detection and stricter law enforcement on those that flout the conservation rules.
\end{abstract}

DOI: $\underline{\text { https://dx.doi.org/10.4314/jasem.v23i6.12 }}$

Copyright: Copyright $(\subset 2019$ Akinsorotan et al. This is an open access article distributed under the Creative Commons Attribution License (CCL), which permits unrestricted use, distribution, and reproduction in any medium, provided the original work is properly cited.

Dates: Received: 27 April 2019; Revised: 22 May 2019; Accepted 11 June 2019

Keywords: biodiversity conservation, sensitive behaviors, compliance, randomized response technique

Illegal resource use threatens natural resource conservation in the developing world (Brashares et al., 2011; Muhumuza and Balkwill, 2013). Despite the establishment of protected areas, the problem of natural resource conservation seem unsolved due to various degree of threat evolving from activities such as farm encroachment, collection of fuel wood, mining, logging, hunting and livestock grazing (Tranquilli et al., 2014). Such activities are covert and require strengthening park management through enforcement, thus the lower an individual's level of income, the lower is his opportunity cost of engaging in illicit activities (Nuno et al., 2013). Given the unprecedented/unending threats and the associated impact on natural resources, determining the extent of illegal resource use is challenging (Nuno et al., 2013). Natural resource management has used various techniques in counting the number of knownoffenders, calculating patrol effort and signs of illegal activity. Social scientists have used other techniques such as economic modeling, ethnology, decision tree analyses, focus groups, market studies and selfreporting to estimate illegal activity (Solomon et al., 2007). Natural resource managers also employ the use of key informants on obtaining information regarding illegal resource activity. The effectiveness of these techniques for quantifying illegal resource use is limited by methodological constraints, timeconsuming and expensive, especially in developing countries where resources are stretched thin over large geographical areas (Solomon et al., 2007). Often the techniques do not account for the number of people violating the law as offenders may emerge from a particular group or across the neighboring community's collecting resources illegally and therefore have limited policy implications (Solomon et al., 2007). The present day natural resource managers now employ various strategies (e.g. increase regulation, community-based programs and integrated development programs) to addressing illegal resource use (Nuno et al., 2013). However, understanding who the illegal resource users are (young male, low income earners) and how many of them exist (small portion of a community or a majority) are vital information required for an appropriate design of conservation interventions (Solomon et al., 2007). Such data driven interventions are effective in achieving conservation goals (Fanelli, 2009). Unfortunately, in conservation and natural resource management, many of the setbacks in achieving sustainability and conservation are sensitive. Those involved in the illicit act often do not wish to admit or identify themselves for the fear of retribution (Gavin et al., 2010). Asking a person directly if he/she has violated the law may not produce 
a true response. Therefore, determining illegal resource use is a sensitive topic. Given the sensitivity of such study, respondents have a strong incentive to lie under direct questioning admitting to activities such as poaching (Chang, 2017) or illegal extraction from natural resource in protected areas. Sensitive and or embarrassing issues tend to be underreported in surveys (McNeeley, 2013). This can systematically bias data collection, decreasing the accuracy of information and producing questionable results (Fanelli, 2009). An alternative method for studying sensitive behaviors is the Randomized Response Technique (RRT) (Warmer 1965). RRT increases the respondents' propensity and inclination to respond more accurately than direct questioning (Razafimanahaka et al., 2012). Guaranteeing anonymity increases response rate and data validity when topic under investigation is sensitive. RRT provides respondents with an additional assurance of privacy beyond that achieved by ensuring respondent anonymity. This is achieved by using a randomizing device to add an element of chance to the question answer process. RRT has been shown to increase the validity of data on sensitive topics in a variety of contexts such as illegal abortion (St John et al., 2012) and exploitation of natural resource (Solomon et al., 2007; St John et al., 2012). Despite their promise, few studies have applied RRT to natural resource management problem.

To this end, this study aimed at assessing the extent of illegal resource exploitation in a forest reserve in Nigeria.

\section{MATERIALS AND METHODS}

Study area: The local communities surrounding the Oba Hills Forest Reserve (OHFR) (Figure 1) traditionally are agrarian and hunters. The villages are multiethnic but mostly dominated by the Yoruba (the indigenes). The other ethnic group found in this area owe largely to immigration. Households are large and education is up to primary level. Any unauthorized entry or all forms of human activities such as farming, logging, grazing of domestic animals, hunting etc. are illegal and monitored by the forest guards and personnel of the Osun State Ministry of Environment.

Data collection: This study employed Randomized Response Technique (RRT) to estimate prevalence of illegal natural resource extraction/use. Using a purposive sampling design, survey respondents were randomly selected. The RRT has been used within conservation or natural resource management and therefore, it has been confirmed appropriate to be used in this study.

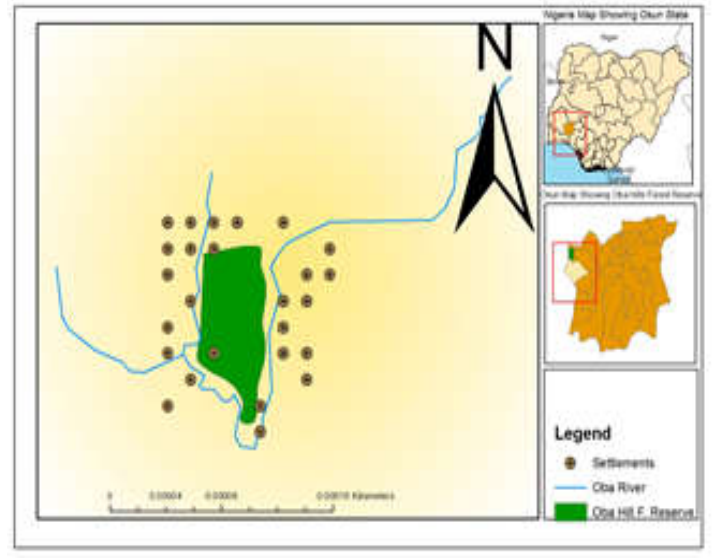

Fig 1: Map showing Oba Hills Forest Reserve and surrounding Settlement

Data were collected from eight (8) villages at close proximity to the reserve (within $5 \mathrm{~km}$ radius) which were randomly selected. Using a cluster sampling method, a total of 234 household heads were randomly selected across the eight villages. The surveys were conducted by the research team comprising of the author and a research assistant. Interviewers used a non-conventional means of randomization to minimize spatial autocorrelation between neighboring households due to lack of household heads record/data for each village. Therefore, 1 household is selected in each village and then skipped 2 households before approaching the next household to interview. Interviews were conducted with the head of household or any other household member provided they were 18 years old or older. If a suitable respondent was not present, an adjacent household was surveyed instead. Approximately $1.5-9.7 \%$ of the households in each village were sampled. The survey instrument (questionnaire) used was adapted from St. John et al., (2012). The survey was made up of two short sections: RRT questions and basic demo-graphics. The RRT questions comprise seven short questions (openended) in binary scale format. RRT questions referred to the last 12 months to minimize recall inaccuracy while also allowing an adequate time for the behavior to have occurred. The forced response RRT (LensveltMurders et al., 2005) design was employed in this study. Although, the method is not forced as the name implies, however, the respondents are instructed to answer a sensitive question in a form of a game. A black bag of 8 white balls, 1 red ball and 1 black ball was handed over to participant from where a ball will be chosen once at a time. If respondent chooses a white ball, he must answer the question truthfully. If red, respondent must answer 'Yes' irrespective of the truthful answer to the question and If black ball was chosen, respondent must say 'No' to the question no 
matter what the truthful answer is. The rules of this survey ensures that respondent remain anonymous, as none of their answers can be traced back to them.

Data analysis: The data were analyzed by

$$
\pi=\frac{(\lambda-\theta)}{S}
$$

Where л is the estimated proportion of the sample who have undertaken the behavior, $\lambda$ is the proportion of all responses in the sample that are 'yes', $\theta$ is the probability of the answer being a 'forced yes', $S$ is the probability of having to answer the sensitive question truthfully.

\section{RESULTS AND DISCUSSION}

For all the RRT questions, Cronbach's alpha coefficient was above 0.7 showing high internal consistency. Two hundred and thirty-four (100\%) household heads gave oral consent and participated in the survey. Majority of the respondents $(78.5 \%, \mathrm{n}=$ 234) were male, the mean age was 43 years $(\mathrm{SE}=0.98$, $\mathrm{n}=234$ ). Over half of the household heads belongs to the Yoruba ethnic group $(67.95 \%)$, and married (69.7\%). Most respondents (42.7\%) have household size of 6 - 9 individuals while over one - third have completed primary (38.5\%) and secondary (34.6\%) level of education respectively. Prior to the questions subjected to RRT, a test question "Do you know how to play draft?" was asked to the villagers to assess their understanding of the technique, $17.7 \%$ answered No and $82.3 \%$ answered Yes, RRT estimate shows that $100 \%($ RRT $=1.03)$ of the respondents plays draft. Furthermore, $85 \%(\mathrm{RRT}=0.85)$ of the villagers grow their crop evident to the fact that the common occupation of the villagers is crop farming. Majority of the villagers $(87 \%$, RRT $=0.87)$ have entered the reserve since its inception and even to the last seven (7) days prior to the administration of questionnaires for this survey. This is an indicator of ineffective security and conservation measures in OHFR. Annually, 88\% $(\mathrm{RRT}=0.88)$ of the villagers reported to have encroached the reserve to farm or plant crops as well as engaging in other illegal activities which reduce the potentials of natural resources therein. Timber logging $(74 \%$, RRT $=0.74)$, firewood gathering $(82 \%, \mathrm{RRT}=0.82)$ and hunting $(62 \%, \mathrm{RRT}=0.62)$ are other negative impact activities as estimated from the villagers' survey with no penalty reported. This is an indicator that the livelihood (farming) of the villagers is detrimental to the existence of the reserve.

Table 1: Descriptive analysis of Randomized Response Techniques of villager survey

\begin{tabular}{|c|c|c|c|c|}
\hline $\mathrm{S} / \mathrm{N}$ & Variable & Percentage $(\%)$ & Equation & RRT Estimate \\
\hline \multirow[t]{3}{*}{ Example } & Do you know how to play draft & & $973-0.1 / 0.8$ & \\
\hline & No & $43(17.70)$ & & \\
\hline & Yes & 191(82.3) & $.823-0.1 / 0.8$ & 1.03 \\
\hline \multirow[t]{3}{*}{1} & do you grow your own crop & & & \\
\hline & $\mathrm{No}=1$ & $51(21.80)$ & & \\
\hline & Yes $=2$ & $183(78.21)$ & $.782-0.1 / 0.8$ & .85 \\
\hline \multirow[t]{3}{*}{2} & $\begin{array}{l}\text { since the inception of the Oba hills forest reserve have you entered } \\
\text { the forest reserve }\end{array}$ & & & \\
\hline & No $=1$ & $47(20.09)$ & & \\
\hline & Yes $=2$ & $187(79.91)$ & $.799-0.1 / 0.8$ & .87 \\
\hline \multirow[t]{3}{*}{3} & Did you enter the forest reserve last week? & & & \\
\hline & No $=1$ & $48(20.51)$ & & \\
\hline & Yes $=2$ & $186(79.49)$ & $.795-0.1 / 0.8$ & .87 \\
\hline \multirow[t]{3}{*}{4} & $\begin{array}{l}\text { In the last } 12 \text { months did you ever enter the forest to farm/or plant } \\
\text { crops }\end{array}$ & & & \\
\hline & No $=1$ & $46(19.66)$ & & \\
\hline & Yes $=2$ & $188(80.34)$ & $.803-0.1 / 0.8$ & .88 \\
\hline \multirow[t]{3}{*}{5} & $\begin{array}{l}\text { In the last } 12 \text { months did you ever enter the forest reserve to } \\
\text { extract/get timber? }\end{array}$ & & & \\
\hline & $\mathrm{No}=1$ & $73(31.20)$ & & \\
\hline & Yes $=2$ & $161(68.80)$ & $.688-0.1 / 0.8$ & .74 \\
\hline \multirow[t]{3}{*}{6} & $\begin{array}{l}\text { In the last } 12 \text { months did you ever enter the forest reserve to get } \\
\text { firewood? }\end{array}$ & & & \\
\hline & No $=1$ & $57(24.36)$ & & \\
\hline & Yes $=2$ & $177(75.64)$ & $.756-0.1 / 0.8$ & .82 \\
\hline \multirow[t]{3}{*}{7} & In the last 12 months did you ever enter the forest reserve to hunt? & & & \\
\hline & No $=1$ & $82(35.04)$ & & \\
\hline & Yes $=2$ & $152(64.96)$ & $.650-0.1 / 0.8$ & .69 \\
\hline
\end{tabular}

The study of human disturbance inside protected landscape is rare (Robbins et al., 2006). Quantifying natural resource extraction/use is a major challenge in most protected landscape due to the dynamic and concealed nature of these illegal human behaviors (St.
John et al, 2012). This present study investigates prevalence of such behavior using a novel method that ensures respondents anonymity (St. John et al, 2012; Nuno et al., 2013). In an attempt to estimate the prevalence of natural resource extraction in OHFR, the 
result shows that more than 60 per cent of the villagers encroach the reserve to farm, log timber, gather firewoods and hunt in the last 12 months. This present findings are worrying given the primary objective of protected areas (to safeguard the biodiversity and restrict illegal exploitation of these biological resources). In considering the target, action, context and time scale of these rule breaking behaviors as suggested by Conner and Sparks (2008) by the villagers, it is evident that the target species poached are the biological resources (large mammals to rodents) found within the reserve and overtime have evolved to a traditional or alternative means of livelihood. For example, the decision to poach is assumed to be determined by the material gain of noncompliance relative to the cost of sanctions imposed. The livelihood of local people depend solely on forest resources for bushmeat as animal protein substitute, biomass fuel as firewood to cook food and to heat their homes (Brashares et al., 2010). In many developing countries, more than 80 percent of total energy consumed comes from forests and related biomass. Biodiversity loss in recent times around protected areas is a major problem (Hughes et al., 1997), blowing down biodiversity loss and rate of illegal exploitation will require an understanding of the behaviors that drive the loss. The unmonitored, unregulated and unsustainable rate of timber logging in OHFR may probably not only result in biodiversity loss but also contributes to global deforestation of forest cover and global warming that is taking place at an alarming rate. Protected areas harbor great biological richness and are a major source of material and non-material wealth, representing a blend of indispensable array of ecosystem practices (Solomon et al., 2013). However, illegal timber logging, firewood fetching and other forms of illegal activities continues to form a non-genetic traits being passed from generation to generation. Nevertheless, the extent of the environmental risk of the human predicament is still unknown to the vast majority of the general public and decision makers worldwide (Gavin et al., 2010) particularly because of its' illegal nature (Gavin et al., 2010). This present study further suggests that high proportion of the villagers grow their own crops, this interprets to be that they participate in crop farming as a means of livelihood. These findings corroborate with past authors who reported crop farming at subsistence level as the primary occupation of the villagers surrounding OHFR. Farming (subsistence crop farming) as a primary occupation is a seasonal type of employment and those engage in it could be face with difficult livelihood during the lean season (dry season, drought and/or crop failure). In such difficult situation, hunting remains an alternative source of livelihood to meet household's domestic and nutritional needs. This finding agrees with past authors who suggested that hunting is predominately for cash and primary sources of income may not be sufficiently attractive to compete with the opportunities provided by hunting (Nuno et al., 2013). Reducing exploitation of natural resources could be critical to their loss and the ecosystem services provided for the present and future generation. This research thereby reveals not just the direct effects of illegal exploitation of natural resources but also the cascading effects to which the ecosystem are subjected as localized anthropogenic activities strongly affect biodiversity across broad landscapes. Law enforcements, park monitoring, conservation educations and other intervention schemes become a threat rather than solution if not considered in the management plan. As studies geared towards understanding the attitude of locals towards conservation increases, much attention should also be given to conservation programs and interventions (alternative livelihood) that aim at changing their behavior of interest

\section{REFERENCES}

Brashares, JS; Golden, CD; Weinbaum, KZ; Barrett, CB; Okello, GV (2011). Economic and geographic drivers of wildlife consumption in rural Africa. Proc. Nat. Acad. Sci. USA. 108 (34), 13931-13936.

Fanelli, D (2009). How Many Scientists Fabricate and Falsify Research? A Systematic Review and Meta-Analysis of Survey Data. Pub. Lib. of Sci. 4(5): e5738.

Gavin, MC; Solomon, JN; Blank SG (2010). Measuring and monitoring illegal use of natural resources. Conserve. Biol. 24: $89-100$

Hughes, JB; Daily, GC; Ehrlich, PR (1997). Population diversity: Its Extent and Extinction. Sci. 278: 689-692

Muhumuza, M; Balkwill K (2013). Factors affecting the success of conserving biodiversity in National parks: A review of case studies from Africa. Inter. J. Biol. http://dx.doi.org/10.1155/2013/798101 Accessed $\underline{04 / 05 / 2015}$

McNeeley, S (2013). Sensitive Issues in Surveys: Reducing Refusals While Increasing Reliability and Quality of Responses to Sensitive Survey Items from book An Overlooked Approach in Survey Research: Total Survey Error, Springer, pp.377-396. 
Nuno, A; Bunnefeld, N; Naiman, CL; Milner-Gulland. EJ (2013). A Novel Approach to Assessing the Prevalence and Drivers of Illegal Bushmeat Hunting in the Serengeti. Conserve. Bio. 27(6): 1355-1365

Razafimanahaka, J; Jenkins, RB; Andriafidison D; Randrainandrainina F; Kotomboavonjy V; Keane A;. Jones, JPG (2012). Novel approach for quantifying illegal bushmeat consumption reveals high consumption of protected species in Madagascar, Inter. J. Conserve. 46(4): 584-592

Solomon, J; Jacobson, SK; Kenneth, D; Gavin M (2007). Estimating illegal resource use at a Ugandan park with the Randomized Response Technique, Hum Dimension. Wild, 2(2): 75-88.
Solomon, J; Jacobson, S; Wild, KD; Gavin, M (2013). Estimating illegal resource use at a Ugandan Park with the Randomized Response Technique. Hum. Dimension. Wild. 12(2):75-88

Tranquilli, S; Abedi-Lartey, M; Abernethy, K; Amsini, F; Asamoah, A (2014). Protected Areas in Tropical Africa: Assessing Threats and Conservation Activities. PLoS ONE 9(12): e114154. doi:10.1371/journal.pone.0114154

Warmer, SL. 1965. Randomized response: A survey technique for eliminating evasive answer bias. $J$. Am. Stat. Ass. 60(309):63-69. 